\title{
The Impact of Learner-Related Variables on Second Language Incidental Vocabulary Acquisition through Listening
}

\author{
Sarvenaz Hatami \\ California State University Long Beach \\ doi: http://dx.doi.org/10.7820/vli.v06.1.Hatami
}

\begin{abstract}
Little is known about the complex process of L2 incidental vocabulary acquisition from listening and the factors that contribute to its success. To expand our knowledge in this area, the present study investigated the impact of five learner-related variables on L2 incidental vocabulary acquisition from listening. These variables were gender, L2 vocabulary knowledge, amount of L2 listening (for academic purposes and pleasure), level of enjoyment, and (self-reported) level of comprehension. Ninety-nine Iranian English as a foreign language (EFL) learners at pre-intermediate levels of English proficiency were randomly assigned to a listening group and a control group. Sixteen target words were chosen in a graded reader and were then replaced by 16 English-like non-words. The participants listened to the graded reader containing the 16 non-words and completed a vocabulary post-test immediately after the listening session. The posttest measured participants' knowledge of five different dimensions of word knowledge at the level of recognition. The findings revealed that while gender and amount of L2 listening appear to have no impact on incidental vocabulary gains from listening, L2 vocabulary knowledge, level of enjoyment, and level of comprehension are important facilitating factors.
\end{abstract}

\section{Introduction}

Before the 1970s, listening was assumed to be a receptive language skill in which listeners passively assimilate messages from incoming speech (Morley, 1984, as cited in Murphy, 1991). Today, listening comprehension is described as a far more complex process, critical to second-language (L2) acquisition, and the most difficult of the four language skills to learn (Vandergrift, 2004). Not unexpectedly, incidental vocabulary acquisition from listening is also a complex process involving many different factors. In his review essay on factors affecting the incidental acquisition of L2 vocabulary from oral input, Ellis (1994) emphasized that very little attention had been paid to this area of research. Surprisingly, after more than 20 years, the need for further study still exists. While there is a considerable amount of research on L2 incidental vocabulary acquisition through reading, research on L2 incidental vocabulary acquisition through listening is scarce (Brown, Waring, \& Donkaewbua, 2008; van Zeeland \& Schmitt, 2013a; Vidal, 2003). As a result, little is known about the development of vocabulary knowledge from L2 listening and the word-, text-, task-, and learner-related variables that 
play a role in this process. Nevertheless, the importance of L2 incidental vocabulary acquisition through listening cannot be underestimated, and children's sizeable vocabulary development in their first language (L1), before learning to read, attests to this (Ellis, 1994).

The objective of this work, therefore, was to explore some of the learnerrelated variables that might contribute to L2 incidental vocabulary acquisition from listening. Studies have shown that listening is a less effective input mode than reading for L2 incidental vocabulary acquisition (Brown et al., 2008; Hatami, 2017; Vidal, 2011). L2 learners have also reported that listening is their least preferred input mode when compared to reading and reading-while-listening (Brown et al., 2008). In order to better understand and ultimately reduce the complications learners face in L2 incidental vocabulary acquisition from listening, more needs to be known about this complex process and the factors that contribute to its success.

The learner-related variables chosen for inclusion in the present study were gender, L2 vocabulary knowledge, amount of L2 listening (for academic purposes and pleasure), level of enjoyment, and (self-reported) level of comprehension. L2 research has shown that these variables play a role in incidental vocabulary acquisition from reading (e.g., Elgort \& Warren, 2014); in this study, the aim was to determine whether these learner-related variables also play a role in L2 incidental vocabulary acquisition from listening. Reading and listening, despite their differences, share important comprehension processes; for instance, they both involve decoding and interpretation using two basic knowledge sources: linguistic knowledge and world knowledge (Vandergrift \& Baker, 2015). Because of such important similarities, and also because L2 listening research is limited, "it is common practice for listening researchers to use reading-based findings as their starting point" (van Zeeland, 2014, p. 1007).

In addition to evidence from L2 reading research, a number of listening studies, although not directly focused on incidental vocabulary acquisition, indirectly suggest that some of the learner-related variables chosen for this study might play a role in incidental vocabulary acquisition from listening. Regarding the role of gender, for instance, differences between males and females have been reported in strategy use while listening in the L2 (Bacon, 1992). However, there are also studies which have failed to show any significant gender differences in L2 listening comprehension ability (e.g., Bacon, 1992; Feyten, 1991; Vandergrift, 2006) or strategy use (Vandergrift, 1997). Furthermore, L2 vocabulary knowledge has been shown to be an important factor for successful L2 listening comprehension (Mecartty, 2000; Stæhr, 2009). And finally, enjoyment and L2 listening comprehension have been shown to be closely related (Ducker \& Saunders, 2014).

\section{Literature Review}

\subsection{Factors Affecting L2 Incidental Vocabulary Acquisition through Listening}

L2 research has shown that both reading and listening can be a source of incidental vocabulary acquisition. However, while L2 incidental vocabulary acquisition through reading and the factors involved have been widely examined, 
research on factors contributing to L2 incidental vocabulary acquisition through listening, particularly learner-related factors, is very limited. Vidal (2003) investigated the impact of two learner-related variables, L2 proficiency and lecture comprehension, on incidental vocabulary acquisition from academic listening with 116 university-level Spanish EFL learners. The findings revealed that both L2 proficiency and lecture comprehension impact the degree to which vocabulary is gained from academic listening: the higher the level of L2 proficiency and lecture comprehension, the greater the vocabulary gains. Moreover, in a study with 172 Chinese university EFL learners at pre-intermediate to intermediate levels of language proficiency, Chang (2012) examined the relationship between metacognitive listening awareness, listening comprehension, and incidental vocabulary acquisition, and found that they are related; however, the correlations were generally not strong.

In addition, a few studies have examined the word- and task-related variables that could play a role in L2 incidental vocabulary acquisition through listening. These variables include: frequency of word occurrence in the text (Brown et al., 2008; Hatami, 2017; van Zeeland \& Schmitt, 2013a; Vidal, 2003, 2011); predictability from word form and parts (i.e., unpredictable, deceptively transparent, morphologically predictable, similar to L1); word type (i.e., low-frequency, technical, academic); type of elaboration (i.e., explicit, implicit, no elaboration) (Vidal, 2003, 2011); part of speech; concreteness (van Zeeland \& Schmitt, 2013a); and repetition of the listening text (Chang, 2012).

As the above review indicates, the L2 studies that have explored the impact of certain variables on L2 incidental vocabulary acquisition from listening are too few in number to allow any general conclusions. Therefore, attempts at establishing previous findings or exploring new variables would be worthwhile, and this is what this study set out to accomplish, by focusing on learner-related variables, which previous research has examined to a surprisingly limited extent.

\subsection{Depth of Vocabulary Knowledge}

Depth of vocabulary knowledge is a broad, vague, and imprecisely-defined construct, which L2 researchers have conceptualized and measured in different ways (Schmitt, 2014). A common approach to describing depth of vocabulary knowledge is to draw a distinction between receptive vocabulary knowledge (i.e., the ability to comprehend lexical items during reading or listening) and productive vocabulary knowledge (i.e., the ability to produce lexical items during speaking or writing). One way of conceptualizing depth of vocabulary knowledge is to think of vocabulary knowledge along a continuum of mastery; as more and more is acquired about a word, mastery of the word gradually shifts from the receptive end toward the productive end of the continuum (Melka, 1997). However, if there really is a continuum, the location of "the threshold at which the word passes from receptive to productive status" is unclear (Read, 2000, p. 154). Other scholars have viewed the acquisition of depth of vocabulary knowledge along a set of discrete stages (rather than along a continuum) and have used progression scales for its measurement (e.g., Wesche \& Paribakht, 1996); however, such scales have long been the subject of criticism (Schmitt, 2010). Meara (1997) proposes another conceptualization of depth of vocabulary knowledge, which tends to focus 
on the lexicon as a whole, rather than on isolated words. According to Meara, the mental lexicon consists of an interrelated network of lexical items; when a new word is acquired, it is integrated into this network of already-known items. Based on this view, the greater the degree of integration of a word into this network, in other words, the greater the number of links between a word and its related items (through associations, collocations, etc.), the greater its depth. However, as Schmitt (2014) points out, while this approach seems very promising, "unfortunately, our understanding of lexical organization is not yet advanced enough to pursue this direction in a tangible way" (p. 943). Another well-known approach to conceptualizing depth of vocabulary knowledge is termed the dimensions or components approach (Read, 1997; Schmitt, 2010). In this approach, which is known as one of the most effective ways of measuring depth of vocabulary knowledge (Nation \& Webb, 2011), vocabulary knowledge is broken down into various isolated dimensions (see Table 1 for the nine different dimensions of word knowledge proposed by Nation, 1990, 2001). Receptive or productive knowledge of each dimension is then separately measured.

In the present study, the vocabulary knowledge gained through listening was conceptualized and measured using the dimensions approach. While the dimensions approach has been used quite extensively in L2 reading studies on incidental vocabulary acquisition, only two of the L2 listening studies reviewed above have used the dimensions approach to measure incidental vocabulary gains (i.e., Hatami, 2017; van Zeeland \& Schmitt, 2013a). Other L2 listening studies have either used a scale (i.e., Chang, 2012; Vidal, 2003, 2011) or have only measured one or two dimensions of word knowledge, that is, written form and/or form-meaning connection (i.e., Brown et al., 2008; Chang, 2012). As van Zeeland and Schmitt point out, since "learning gains from listening have [been] found to be small, even significantly smaller than those from reading, the dimensions approach should serve particularly well in revealing the smallest increments in learning" (p. 611).

\section{The Present Study}

In this study, the impact of five learner-related variables on L2 incidental vocabulary acquisition through listening was examined. The learner-related variables were gender, L2 vocabulary knowledge, amount of L2 listening (for academic purposes and pleasure), level of enjoyment, and (self-reported) level of comprehension. Although word-, text-, and task-related variables can also play an important role in L2 incidental vocabulary acquisition from listening, the primary focus here was on variables related to the learner/listener, in the hope that additional research will extend to other variables.

Table 1. What Is Involved in Knowing a Word (Nation, 1990, 2001)

\begin{tabular}{lll}
\hline Form & Meaning & Use \\
\hline Spoken form & Form-meaning connection & Grammatical functions \\
Written form & Concept and referents & Collocations \\
Word parts & Associations & Constraints on use (e.g., register, frequency) \\
\hline
\end{tabular}

Vocabulary Learning and Instruction, 6 (1), 1-20. 


\section{Method}

\subsection{Participants}

Ninety-nine undergraduate students (57 males, 42 females) majoring in engineering at a high-ranking university in Iran participated in this study. The participants ranged in age between 18 and 24 years $(M=19.58, \mathrm{SD}=1.36)$ and all spoke Farsi as their L1. They had all formally studied English for 7 years at school before entering university, and none had ever lived in an English-speaking country. The vocabulary knowledge of the participants was determined using the Vocabulary Levels Test (VLT) (Schmitt, Schmitt, \& Clapham, 2001). The mean scores on the 2,000, 3,000, and 5,000 word levels of the VLT were $23.07,15.13$, and 7.43 , respectively (maximum score at each level $=30$ ). Only participants with at least 50\% mastery of the 2,000 word level were included in the study. This cut-off point was determined to ensure that participants had knowledge of the running words in the listening text and could therefore understand the text with little or no difficulty. None of the participants reported hearing difficulties. All participants received cash incentives (equivalent to \$10 CAD) for their participation. The participants were randomly assigned to a listening group $(n=51)$ and a control group $(n=48)$.

\subsection{Materials}

\subsubsection{Target words}

For the purposes of this study, non-words were used, that is, words created by a complete change in the form of already known, common concepts (Waring \& Takaki, 2003). Learning such non-words is the simplest level of learning a new word, as it only involves learning a new label, and not a new concept (Nation, 2001). Nevertheless, using such non-words in L2 research for lower proficiency learners such as those in this study is acceptable and common. This is because, firstly, in the initial stages of L2 learning, L2 vocabulary acquisition does not involve learning many new concepts; rather, learners typically acquire L2 word forms for their already-existing L1 concepts (Nation \& Webb, 2011). Secondly, providing 95\%-98\% lexical coverage - which is known to provide adequate comprehension of spoken texts (Stæhr, 2009; van Zeeland \& Schmitt, 2013b) —with truly unknown target words (i.e., words whose form and meaning are both unknown) often necessitates heavy adaptation of the text, since truly unknown words are typically infrequent words that tend to occur with other low-frequency words (Webb, 2005); and the heavy adaptation of the text can compromise the ecological validity of the study.

Sixteen words in the listening text were chosen as target words. The target words were then substituted throughout the text with 16 non-words (see Appendix A). Several steps were taken to ensure that the non-words looked like plausible English words and were equivalent, as much as possible, in terms of learning difficulty. First, 46 non-words, all two-syllabic and five or six letters in length, were chosen from Meara's (2013) list of imaginary words. Next, three TESL experts judged the non-words with regard to their plausibility as real English words. Consequently, 16 of the 46 non-words were excluded due to one of the following

Vocabulary Learning and Instruction, 6 (1), 1-20. 
reasons: the non-word had irregular pronunciation and/or spelling, contained a real English word, was a popular English first/last name, or looked French. A questionnaire was then developed for the remaining 30 non-words and was administered to five native English speakers (mean age $=38$ years) and five Iranian non-native English speakers (mean age $=29.8$ years). The questionnaire asked the respondents, in a yes/no question, whether each non-word resembled a real English word. It also required the respondents to rate each non-word, on a scale of $1-5$, in terms of its spelling and pronunciation difficulty $(1=$ very easy; $5=$ very difficult). Based on the responses to the questionnaire, 16 of the non-words were selected to be used in the study. These 16 non-words were rated as plausible English words by at least 8 of the 10 respondents to the questionnaire, and their average spelling difficulty and pronunciation difficulty were rated lower than 3 on the 5-point scale.

\subsubsection{Listening material}

The listening text chosen for this study was The Monkey's Paw, an elementary-level graded reader selected from the Oxford Bookworms series. To ensure that participants had knowledge of all the running words in the text, the text was further simplified. First, the researcher (a native Farsi speaker) changed the proper nouns which were thought to be unfamiliar to the participants to more familiar ones (e.g., Herbert was changed to Jack). In addition, using the BNCCOCA-25 vocabulary profiler available at www.lextutor.ca/vp/, words in the text that were beyond the 1,000 word-level were either substituted with words from this level or eliminated. The final text contained 4,231 words, and after inserting the non-words, a lexical coverage of $95.84 \%$ was reached. A lexical coverage of 95\%-98\% has been shown to provide adequate comprehension of spoken texts (Stæhr, 2009; van Zeeland \& Schmitt, 2013b).

The final version of the text with the inserted non-words was audio-recorded as it was read aloud by a TESL professor who was a native speaker of Canadian English. The duration of the narration was $36 \mathrm{~min}$, with an average speech rate of 117.5 words per minute.

\subsection{Instruments}

\subsubsection{Language background questionnaire}

The language background questionnaire, translated into Farsi, was designed to collect a range of information about the participants. In addition to demographic information (i.e., gender, age, native country, native language, other languages spoken, and proficiency levels in those languages), participants reported whether or not they had lived in an English-speaking country and how long they had studied English outside of school and university. Moreover, the participants were asked to estimate the amount of time that they spent in a typical week listening to English materials for academic purposes (e.g., lectures, language learning CDs) and for pleasure (e.g., movies, radio, audio books). The two purposes for listening were separated, in order to help learners more accurately calculate their 
amount of L2 listening in a typical week. Because of the EFL context of the learners and the very low possibility of learners engaging in English conversations, conversational listening was not included in the questionnaire.

\subsubsection{Vocabulary Levels Test}

The VLT, originally developed by Nation (1983) and updated and validated by Schmitt et al. (2001), was used in this study to measure L2 vocabulary knowledge. The VLT, which is a test of receptive vocabulary knowledge, consists of four sections that represent four distinct word frequency levels (the 2,000, 3,000, 5,000 , and 10,000 frequency levels) as well as a section for academic vocabulary. In this study, because the 10,000 word level appeared to be beyond the vocabulary knowledge of the participants, only the sections related to the 2,000,3,000, and 5,000 word levels were administered. In scoring, each word correctly chosen was awarded one point. Because each section had 30 test items, and three sections were used in this study, the maximum possible score was 90. Cronbach's alpha for the entire test (all three sections together) was 0.85 .

\subsubsection{Vocabulary post-test}

To capture the vocabulary knowledge gained through listening, five dimensions of word knowledge were selected from the nine proposed by Nation (1990, 2001): spoken form, written form, part of speech, syntagmatic association, and form-meaning connection. All these five dimensions were measured at the level of recognition, and therefore, the vocabulary post-test consisted of five tests (see Appendix B). The post-test was adapted from the works of Webb (2005), Chen and Truscott (2010), and van Zeeland and Schmitt (2013a).

Each of the five tests appeared on two consecutive pages facing each other, with 8 (of the 16) target words on one page and another 8 on the next. Moreover, on the back of the last page of the post-test, two 5-point scales were provided to measure learners' level of enjoyment from listening to the story and level of understanding of the story (see Appendix C). Following Webb (2005), the tests were sequenced so that any possibility of learning effect was avoided. For example, recognition of the written form preceded recognition of form-meaning connection because the correct response to the former was provided in the latter. Instructions for all sections of the post-test appeared in both Farsi and English. Participants were asked to avoid making any changes to the answers they had provided in previous sections of the post-test and, as they were taking the post-test, they were carefully supervised to ensure this. (An easier and more reliable alternative could have been to collect the tests from the participants immediately after each section was completed.) The five recognition tests were scored dichotomously.

\subsection{Procedures}

Before collecting data, the materials and instruments were piloted with four Iranian EFL learners with characteristics similar to those of the population under study; consequently, changes were made to some of the instructions

Vocabulary Learning and Instruction, 6 (1), 1-20. 
and Farsi translations. Data were then collected during two sessions that were 2 weeks apart:

\subsubsection{Session one}

If they agreed to participate in the study, participants signed a consent form, after which they were asked to complete the language background questionnaire and the VLT. This session lasted approximately $50 \mathrm{~min}$.

\subsubsection{Session two}

Participants were told that the objective of this session was to listen to a classic English story and to try to understand it. They were not informed of the vocabulary focus of the study or the vocabulary post-test. However, immediately after they listened to The Monkey's Paw (played from a CD), the unannounced vocabulary post-test was administered. This session lasted approximately $75 \mathrm{~min}$.

The control group completed all the abovementioned procedures (i.e., the consent form, language background questionnaire, VLT, and vocabulary posttest), but were not exposed to the listening text.

\section{Results}

In all the analyses reported below, word recognition was calculated by averaging the scores on the five recognition tests (i.e., recognition tests of spoken form, written form, part of speech, syntagmatic association, and form-meaning connection). Table 2 presents descriptive word recognition statistics for the listening group and the control group.

\subsection{Gender}

In order to examine the impact of gender on L2 incidental vocabulary acquisition from listening, a two-way between-subjects ANOVA was conducted with group (listening vs. control) and gender (male vs. female) as the independent variables and recognition scores as the dependent variable. The results of the ANOVA yielded a significant main effect for group, $F(1,95)=48.72, p<0.001$, partial $\eta^{2}=$ 0.34 , power $=1.0$. However, the effects were not significant for gender, $F(1,95)=$ $0.05, p=0.83$, or for the interaction between group and gender, $F(1,95)=0.68$, $p=0.41$. Descriptive statistics are presented in Table 3 .

Table 2. Descriptive Statistics for Group Scores on the Vocabulary Post-test

\begin{tabular}{lccccc}
\hline \multirow{2}{*}{ Group } & $N$ & $M$ & SD & \multicolumn{2}{c}{$95 \%$ Confidence interval } \\
\cline { 5 - 6 } & & & & Lower bound & Upper bound \\
\hline Listening & 51 & 6.24 & 2.56 & 5.52 & 6.95 \\
Control & 48 & 3.10 & 1.62 & 2.63 & 3.57 \\
\hline
\end{tabular}

Note: The maximum possible score is 16 . 
Table 3. Descriptive Statistics for Males and Females

\begin{tabular}{lllll}
\hline Group & Gender & $N$ & $M$ & SD \\
\hline Listening & Male & 28 & 6.44 & 2.63 \\
& Female & 23 & 5.98 & 2.50 \\
Control & Male & 29 & 2.99 & 1.80 \\
& Female & 19 & 3.26 & 1.31 \\
\hline
\end{tabular}

Note: The maximum possible score on the vocabulary post-test is 16 .

\subsection{L2 Vocabulary Knowledge}

To investigate the effect of L2 vocabulary knowledge on L2 incidental vocabulary acquisition through listening, the scores on the 2,000,3,000, and 5,000 word levels of the VLT were combined $(M=45.64, \mathrm{SD}=12.34$, range $=$ 23-78, maximum score $=90$ ). The mean was then used as the cut-point to divide the participants into two groups: those who scored at or above 45.64 were classified as having relatively "extensive" vocabulary knowledge, and those who obtained scores below the mean were classified as having relatively "limited" vocabulary knowledge (see Table 4 for descriptive statistics). Next, a two-way between-subjects ANOVA was run with group (listening vs. control) and L2 vocabulary knowledge (extensive vs. limited) as the independent variables and recognition scores as the dependent variable. The ANOVA revealed a significant effect for group, $F(1,94)=62.60, p<0.001$, partial $\eta^{2}=0.40$, power $=1.0$; for L2 vocabulary knowledge, $F(1,94)=9.05, p<0.05$, partial $\eta^{2}=0.09$, power $=0.85$; and for the interaction between group and L2 vocabulary knowledge, $F(1,94)=8.55, p<0.05$, partial $\eta^{2}=0.08$, power $=0.83$. Simple effects analysis indicated a statistically significant difference between limited and extensive vocabulary knowledge in the listening group $(p<0.001)$, but not in the control group $(p=0.95)$.

\subsection{Amount of L2 Listening}

To examine the impact of the amount of L2 listening on incidental vocabulary gains, participants' number of hours of L2 academic listening in a typical week and number of hours of L2 pleasure listening in a typical week (as reported in their language background questionnaires) were added together. The distribution was skewed and, thus, to divide the participants into two groups, the median (instead of the mean) was chosen as the cut-point $(M=2.95, M d n=2.5$,

Table 4. Descriptive Statistics for L2 Vocabulary Knowledge

\begin{tabular}{lllll}
\hline Group & L2 Vocabulary knowledge & $N$ & $M$ & SD \\
\hline Listening & Extensive & 23 & 7.43 & 2.27 \\
& Limited & 27 & 5.07 & 2.20 \\
Control & Extensive & 24 & 3.12 & 1.68 \\
& Limited & 24 & 3.08 & 1.59 \\
\hline
\end{tabular}

Note: The maximum possible score on the vocabulary post-test is 16 .

One missing case (a participant's score was an outlier in this analysis and therefore excluded). 
$\mathrm{SD}=2.32$, Range $=0-10)$. Those whose number of hours of L2 listening in a typical week fell at or above 2.5 hours were classified as doing relatively "extensive" amounts of L2 listening, and those whose number of hours of L2 listening in a typical week fell below the median were classified as doing relatively "limited" amounts of L2 listening (see Table 5 for descriptive statistics). A two-way between-subjects ANOVA was then performed with group (listening vs. control) and amount of L2 listening (extensive vs. limited) as the independent variables and recognition scores as the dependent variable. The ANOVA yielded a significant main effect for group, $F(1,89)=50.39, p<0.001$, partial $\eta^{2}=0.36$, power $=$ 1.0. However, the effects were not significant for amount of L2 listening, $F(1,89)$ $=2.89, p=0.09$, or for the interaction between group and amount of L2 listening, $F(1,89)=1.13, p=0.29$.

\subsection{Level of Enjoyment}

To investigate the impact of level of enjoyment (experienced while listening to the story) on incidental vocabulary acquisition, the 5-point scale used in the study to measure level of enjoyment was collapsed into a 3 -point scale $(1=$ disagree, $2=$ neutral, $3=$ agree). This was done in the following way: in response to the statement I enjoyed the story, if the participants marked 1 or 2 on the scale, it was regarded as "disagree"; if they marked 3, it was considered "neutral," and if they marked 4 or 5 on the scale, it was considered "agree" (see Table 6 for descriptive statistics). Next, a one-way between-subjects ANOVA was conducted with enjoyment (disagree vs. neutral vs. agree) as the independent variable and recognition scores as the dependent variable. The ANOVA yielded a significant main effect for enjoyment, $F(2,45)$ $=4.55, p<0.05$, partial $\eta^{2}=0.17$, power $=0.75$. Tukey honestly significant difference (HSD) test revealed a statistically significant difference between "agree" and "disagree" ( $p<0.05)$. However, the differences were not significant between "agree" and "neutral" ( $p=0.07)$ or "disagree" and "neutral" $(p=0.84)$.

Table 5. Descriptive Statistics for Amount of L2 Listening

\begin{tabular}{lllcc}
\hline Group & Amount of L2 Listening & $N$ & $M$ & SD \\
\hline Listening & Extensive & 25 & 6.82 & 2.65 \\
& Limited & 25 & 5.58 & 2.37 \\
\multirow{2}{*}{ Control } & Extensive & 24 & 3.15 & 1.83 \\
& Limited & 19 & 2.86 & 1.32 \\
\hline
\end{tabular}

Note: The maximum possible score on the vocabulary post-test is 16.

Six missing cases (the scores of six participants were outliers in this analysis and therefore excluded).

Table 6. Descriptive Statistics for Level of Enjoyment

\begin{tabular}{lllcc}
\hline Group & Enjoyed the Story & $N$ & $M$ & SD \\
\hline \multirow{3}{*}{ Listening } & Disagree & 12 & 4.92 & 2.14 \\
& Neutral & 15 & 5.44 & 2.69 \\
& Agree & 21 & 7.29 & 2.35 \\
\hline
\end{tabular}

Note: The maximum possible score on the vocabulary post-test is 16 .

Three missing cases (three participants did not provide data). 
Table 7. Descriptive Statistics for Level of Comprehension

\begin{tabular}{llccc}
\hline Group & Understood the Story & $N$ & $M$ & SD \\
\hline \multirow{3}{*}{ Listening } & Disagree & 6 & 3.77 & 1.15 \\
& Neutral & 8 & 4.28 & 1.68 \\
& Agree & 34 & 6.96 & 2.48 \\
\hline
\end{tabular}

Note: The maximum possible score on the vocabulary post-test is 16 .

Three missing cases (three participants did not provide data).

\subsection{Level of Comprehension}

To examine the impact of level of comprehension on incidental vocabulary acquisition from listening, similar to the previous section, the 5-point scale used in the study to measure level of comprehension was collapsed into a 3-point scale $(1=$ disagree, $2=$ neutral, $3=$ agree $)$ in the following way: in response to the statement I understood the story, if the participants marked 1 or 2 on the scale, it was regarded as "disagree"; if they marked 3, it was considered "neutral," and if they marked 4 or 5 on the scale, it was considered "agree." Descriptive statistics are presented in Table 7. A one-way between-subjects ANOVA was conducted with comprehension (disagree vs. neutral vs. agree) as the independent variable and recognition scores as the dependent variable. The ANOVA yielded a significant main effect for comprehension, $F(2,45)=8.3, p<0.05$, partial $\eta^{2}=0.27$, power $=$ 0.95 . Tukey HSD revealed a statistically significant difference between "agree" and "disagree" $(p<0.05)$, and between "agree" and "neutral" $(p<0.05)$, but a non-significant difference between "disagree" and "neutral" $(p=0.91)$.

\section{Discussion and Conclusions}

\subsection{Gender}

In this study, males scored higher than females on the vocabulary post-test, but the difference between the two groups was not statistically significant. Hence, it appears that gender had no impact on L2 incidental vocabulary acquisition from listening. Since L2 listening comprehension influences L2 incidental vocabulary acquisition (Vidal, 2003), the lack of gender differences in this study is congruent with studies which have shown that gender does not play a significant role in L2 listening comprehension (e.g., Bacon, 1992; Feyten, 1991; Vandergrift, 2006) as well as studies that have found minimal differences between males and females regarding their self-reported strategy use while listening in the L2 (e.g., Vandergrift, 1997). Hence, although females have generally been considered more successful foreign language learners than males and their greater success is hypothesized to be related to the interaction of neurological, cognitive, affective, social, and educational factors (Rúa, 2006), this superiority does not appear to apply to incidental vocabulary acquisition from listening.

\subsection{L2 Vocabulary Knowledge}

In this study, learners with a larger L2 vocabulary scored significantly higher on the vocabulary post-test than learners with a smaller L2 vocabulary. 
L2 vocabulary knowledge therefore impacts the incidental acquisition of L2 vocabulary through listening. One explanation for this finding is that L2 vocabulary knowledge contributes to L2 listening comprehension (Mecartty, 2000; Stæhr, 2009), and L2 listening comprehension appears to contribute to incidental vocabulary acquisition (Vidal, 2003). In other words, the greater one's L2 vocabulary knowledge and, consequently, L2 proficiency (Stæhr, 2008), the greater the amount of L2 spoken input that can be successfully processed and understood (Vidal, 2003), and thus, the larger the vocabulary gains from that input. Previous reading studies have also shown that $\mathrm{L} 2$ lexical proficiency is an important factor in L2 incidental vocabulary acquisition (Elgort \& Warren, 2014).

\subsection{Amount of L2 Listening}

Although learners who reported more L2 listening in a typical week scored higher on the vocabulary post-test than learners who reported less L2 listening, the difference between the two groups was not statistically significant. Hence, amount of L2 listening did not appear to have an impact on L2 incidental vocabulary acquisition from listening. This finding suggests that mere exposure to more L2 listening opportunities in an EFL context does not significantly enhance one's success in incidental vocabulary acquisition from listening. In addition to repeated practice, it appears that instruction and strategy training in L2 listening comprehension and in the use of context are needed. As Vandergrift (2004) states, "students need to 'learn to listen' so that they can better 'listen to learn"" (p. 3). Considering that EFL education in Iranian formal schools and universities focuses heavily on the grammar-translation method and reading comprehension (Farhady, Hezaveh, \& Hedayati, 2010; Kiany, Mahdavy, \& Samar, 2011), it is not surprising that Iranian EFL learners lack the necessary skills and strategies to take full advantage of their L2 listening and incidental vocabulary acquisition opportunities. This situation exists not only in Iran, but also in other EFL contexts such as Japan (Nishino \& Watanabe, 2008). Learners indeed need to "learn to listen" and learn to pay more attention to context, and, in fact, studies have shown improvements in listening comprehension as a result of L2 listening instruction (Goh \& Taib, 2006) and improvements in incidental vocabulary acquisition from listening (in terms of word form recognition only) as a result of lexical inferencing training (Chang, 2012).

It should also be noted that retrospective reports of the amount of L2 listening in a typical week (as was the case in this study) may not be very reliable and, thus, these results should be interpreted with caution. Asking learners to keep a daily log or journal of their amount of L2 listening over a specified period of time might be a better option for collecting such data.

\subsection{Level of Enjoyment}

The degree to which learners enjoy listening to a text appears to affect L2 incidental vocabulary gains. In this study, in response to the statement I enjoyed the story, those learners who rated "strongly agree" or "agree," scored significantly higher on the vocabulary post-test than those who rated "disagree" or "strongly 
disagree." This result aligns with findings from Ducker and Saunders' (2014) study with intermediate-level Japanese-speaking EFL learners, in which enjoyment and listening comprehension were found to be strongly related. L2 reading studies that have investigated the impact of enjoyment on incidental vocabulary acquisition (e.g., Elgort \& Warren, 2014) have reported similar results. These findings suggest that to enhance L2 listening comprehension and incidental vocabulary gains, materials chosen for L2 listening should be interesting and enjoyable to the learners, which indicates the importance of learners self-selecting the topic and text they wish to listen to, where possible. Enjoying the listening material can be so facilitating that it might even compensate, to some extent, for the lack of adequate language proficiency (Waring, 2010).

\subsection{Level of Comprehension}

In response to the statement I understood the story, those learners who rated "strongly agree" or "agree," scored significantly higher on the vocabulary post-test than those who rated "neutral," "disagree," or "strongly disagree." Hence, level of comprehension impacts L2 incidental vocabulary acquisition from listening. This finding supports Vidal's (2003) study, in which she found that incidental vocabulary gains from academic listening appeared to be influenced by learners' degree of lecture comprehension: the higher the level of comprehension, the greater the vocabulary gains. Chang (2012) also found moderate correlations between L2 listening comprehension and incidental vocabulary acquisition. Similar results have also been reported in L2 reading studies (e.g., Elgort \& Warren, 2014). These findings indicate the importance of helping learners access texts that are at their appropriate level in order to ensure comprehension and, consequently, incidental vocabulary acquisition.

\section{Limitations and Suggestions for Further Research}

A few limitations of this study deserve consideration. First, learners' vocabulary knowledge was measured using the VLT, which is a test of orthographic lexical knowledge. Since, in some learners, phonological and orthographic lexical knowledge may be quite different (Milton \& Hopkins, 2006), it would have been more suitable to use a test of aural vocabulary knowledge in this study, such as the LVLT (McLean, Kramer, \& Beglar, 2015). Second, in order to ensure that learners have knowledge of all the words in the text, the text was run through a word family-based profiler (i.e., the BNC-COCA-25 profiler); however, it should not be assumed that because learners demonstrate knowledge of the base form or most common form on the VLT, they will also have knowledge of all associated derivational forms. Hence, a lemma-based profiler (e.g., the NGSL profiler available at www.lextutor. $\mathrm{ca} / \mathrm{vp} /$ ) might have been more appropriate (see McLean, 2017, for why the lemma or flemma, a word's base form and associated inflectional forms, is likely a more appropriate word counting unit). Third, in this study, because of practical constraints, the vocabulary post-test was mainly in written format; this mismatch between the participants' mode of input and mode of measurement might have placed them at a disadvantage in terms of scores (Alali \& Schmitt, 2012) on three of the five tests, that is, tests of part of speech, syntagmatic association, and form-meaning 
connection. Finally, in this study, retention of incidental vocabulary gains from listening was not addressed. Initially, this was one of the objectives of this study and, in fact, when collecting data, a delayed vocabulary post-test was administered 3 weeks after the immediate post-test. However, when analyzing the data, it was revealed that the immediate post-test had impacted the scores on the delayed posttest. In other words, because of the presence of testing effects, retention scores had not been accurately measured and therefore could not be used and reported in this study. Future research could employ a different research design in order to avoid possible testing effects (see the research design in van Zeeland \& Schmitt, 2013a).

In sum, this study showed that males and females are equally successful at incidentally acquiring vocabulary from listening. Furthermore, the results suggested that simply listening to L2 material may not be adequate to enhance L2 learners' abilities in incidental vocabulary acquisition; explicit instruction might also be needed. Moreover, three facilitating factors for incidental vocabulary acquisition from listening were revealed: L2 vocabulary knowledge, enjoyment from the listening content, and level of comprehension. Hence, learners with a large L2 vocabulary who have access to enjoyable, comprehensible texts are likely to gain more vocabulary from listening. Future research would benefit from identifying other facilitating variables, whether learner-, word-, text-, or task-related. Moreover, in this study, the scores on the five recognition tests measuring the five dimensions of word knowledge were combined. A more detailed analysis, in which each dimension of word knowledge is examined separately, could provide a more in-depth understanding of the process of incidental vocabulary acquisition through listening.

\section{References}

Alali, F.A., \& Schmitt, N. (2012). Teaching formulaic sequences: The same as or different from teaching single words? TESOL Journal, 3(2), 153-180. doi:10.1002/tesj.13

Bacon, S.M. (1992). The relationship between gender, comprehension, processing strategies, and cognitive and affective response in foreign language listening. The Modern Language Journal, 76(2), 160-178. doi:10.1111/j.1540-4781.1992. tb01096.x

Brown, R., Waring, R., \& Donkaewbua, S. (2008). Incidental vocabulary acquisition from reading, reading-while-listening, and listening to stories. Reading in a Foreign Language, 20(2), 136-163.

Chang, L. (2012). Investigating the relationships between Chinese university EFL learners' metacognitive listening strategies and their comprehension and incidental vocabulary acquisition from listening tasks. Doctoral dissertation, University of Auckland, New Zealand.

Chen, C., \& Truscott, J. (2010). The effects of repetition and L1 lexicalization on incidental vocabulary acquisition. Applied Linguistics, 31(5), 693-713. doi:10.1093/applin/amq031 
Ducker, N., \& Saunders, M. (2014). Facilitating extensive listening with nongraded materials in EFL programs. International Journal of Innovation in English Language Teaching and Research, 3(2), 201-245.

Elgort, I., \& Warren, P. (2014). L2 vocabulary learning from reading: Explicit and tacit lexical knowledge and the role of learner and item variables. Language Learning, 64(2), 365-414. doi:10.1111/lang.12052

Ellis, R. (1994). Factors in the incidental acquisition of second language vocabulary from oral input: A review essay. Applied Language Learning, 5(1), 1-32.

Farhady, H., Hezaveh, F.S., \& Hedayati, H. (2010). Reflections on foreign language education in Iran. TESL-EJ, 13(4), 1-18.

Feyten, C.M. (1991). The power of listening ability: An overlooked dimension in language acquisition. The Modern Language Journal, 75(2), 173-180. doi:10.1111/j.1540-4781.1991.tb05348.x

Goh, C., \& Taib, Y. (2006). Metacognitive instruction in listening for young learners. ELT Journal, 60(3), 222-232. doi:10.1093/elt/cc1002

Hatami, S. (2017). The differential impact of reading and listening on L2 incidental acquisition of different dimensions of word knowledge. Reading in a Foreign Language, 29(1), 61-85.

Kiany, G.R., Mahdavy, B., \& Samar, R.G. (2011). Towards a harmonized foreign language education program in Iran: National policies and English achievement. Literacy Information and Computer Education Journal, 2(3), 462-469.

McLean, S. (2017). Evidence for the adoption of the flemma as an appropriate word counting unit. Applied Linguistics. doi:10.1093/applin/amw050

McLean, S., Kramer, B., \& Beglar, D. (2015). The creation and validation of a listening vocabulary levels test. Language Teaching Research, 19(6), 741-760.

Meara, P. (1997). Towards a new approach to modelling vocabulary acquisition. In N. Schmitt \& M. McCarthy (Eds.), Vocabulary: Description, acquisition and pedagogy (pp. 109-121). Cambridge, UK: Cambridge University Press.

Meara, P. (2013). Imaginary words. In C.A. Chapelle (Ed.), The encyclopedia of applied linguistics (pp. 1-4). Malden, MA: Wiley-Blackwell.

Mecartty, F.H. (2000). Lexical and grammatical knowledge in reading and listening comprehension by foreign language learners of Spanish. Applied Language Learning, 11(2), 323-348.

Melka, F. (1997). Receptive vs. productive aspects of vocabulary. In N. Schmitt \& M. McCarthy (Eds.), Vocabulary: Description, acquisition and pedagogy (pp. 84-102). Cambridge, UK: Cambridge University Press.

Milton, J., \& Hopkins, N. (2006). Comparing phonological and orthographic vocabulary size: Do vocabulary tests underestimate the knowledge of some learners? Canadian Modern Language Review, 63(1), 127-147. doi:10.3138/ cmlr.63.1.127

Murphy, J.M. (1991). Oral communication in TESOL: Integrating speaking, listening, and pronunciation. TESOL Quarterly, 25(1), 51-75. doi:10.2307/3587028 
Nation, I.S.P. (1983). Testing and teaching vocabulary. Guidelines, 5(1), 12-25.

Nation, I.S.P. (1990). Teaching and learning vocabulary. New York, NY: Heinle \& Heinle.

Nation, I.S.P. (2001). Learning vocabulary in another language. Cambridge, UK: Cambridge University Press.

Nation, I.S.P., \& Webb, S. (2011). Researching and analyzing vocabulary. Boston, MA: Heinle.

Nishino, T., \& Watanabe, M. (2008). Communication-oriented policies versus classroom realities in Japan. TESOL Quarterly, 42(1), 133-138. doi:10.1002/j.1545-7249.2008.tb00214.x

Read, J. (1997). Vocabulary and testing. In N. Schmitt \& M. McCarthy (Eds.), Vocabulary: Description, acquisition and pedagogy (pp. 303-320). Cambridge, UK: Cambridge University Press.

Read, J. (2000). Assessing vocabulary. Cambridge, UK: Cambridge University Press.

Rúa, P.L. (2006). The sex variable in foreign language learning: An integrative approach. Porta Linguarum, 6, 99-114.

Schmitt, N. (2010). Researching vocabulary: A vocabulary research manual. Basingstoke, UK: Palgrave Macmillan.

Schmitt, N. (2014). Size and depth of vocabulary knowledge: What the research shows. Language Learning, 64(4), 913-951. doi:10.1111/lang.12077

Schmitt, N., Schmitt, D., \& Clapham, C. (2001). Developing and exploring the behaviour of two new versions of the Vocabulary Levels Test. Language Testing, 18(1), 55-88. doi:10.1177/026553220101800103

Stæhr, L.S. (2008). Vocabulary size and the skills of listening, reading and writing. The Language Learning Journal, 36(2), 139-152. doi:10.1080/ 09571730802389975

Stæhr, L.S. (2009). Vocabulary knowledge and advanced listening comprehension in English as a foreign language. Studies in Second Language Acquisition, 31(4), 577-607. doi:10.1017/S0272263109990039

Vandergrift, L. (1997). The comprehension strategies of second language (French) listeners: A descriptive study. Foreign Language Annals, 30(3), 387-409. doi:10.1111/j.1944-9720.1997.tb02362.x

Vandergrift, L. (2004). Listening to learn or learning to listen? Annual Review of Applied Linguistics, 24, 3-25. doi:10.1017/S0267190504000017

Vandergrift, L. (2006). Second language listening: Listening ability or language proficiency? The Modern Language Journal, 90(1), 6-18. doi:10.1111/ j.1540-4781.2006.00381.x

Vandergrift, L., \& Baker, S. (2015). Learner variables in second language listening comprehension: An exploratory path analysis. Language Learning, 65(2), 390-416. doi:10.1111/lang.12105 
van Zeeland, H. (2014). Lexical inferencing in first and second language listening. The Modern Language Journal, 98(4), 1006-1021. doi:10.1111/modl.12152

van Zeeland, H., \& Schmitt, N. (2013a). Incidental vocabulary acquisition through L2 listening: A dimensions approach. System, 41(3), 609-624. doi:10.1016/j. system.2013.07.012

van Zeeland, H., \& Schmitt, N. (2013b). Lexical coverage in L1 and L2 listening comprehension: The same or different from reading comprehension? Applied Linguistics, 34(4), 457-479. doi:10.1093/applin/ams074

Vidal, K. (2003). Academic listening: A source of vocabulary acquisition? Applied Linguistics, 24(1), 56-89. doi:10.1093/applin/24.1.56

Vidal, K. (2011). A comparison of the effects of reading and listening on incidental vocabulary acquisition. Language Learning, 61(1), 219-258. doi:10.1111/j.1467-9922.2010.00593.x

Waring, R. (2010). Starting extensive listening. Retrieved from http://www.robwaring.org/el/starting_extensive_listening.htm

Waring, R., \& Takaki, M. (2003). At what rate do learners learn and retain new vocabulary from reading a graded reader? Reading in a Foreign Language, 15(2), 130-163.

Webb, S. (2005). Receptive and productive vocabulary learning: The effects of reading and writing on word knowledge. Studies in Second Language Acquisition, 27(1), 33-52. doi:10.1017/S0272263105050023

Wesche, M., \& Paribakht, T.S. (1996). Assessing second language vocabulary knowledge: Depth versus breadth. Canadian Modern Language Review, 53(1), 13-40. 


\section{Appendix A}

Target Words and Corresponding Non-Words

\begin{tabular}{lcccl}
\hline Target word & Part of speech & $\begin{array}{c}\text { Number of } \\
\text { occurrences }\end{array}$ & Frequency band & Non-word \\
\hline Chair & N. & 2 & $2-5$ & Bartle \\
Big & Adj. & 3 & Scally \\
Tea & N. & 4 & Lorey \\
Smiled & V. & 5 & Kemble $\rightarrow$ Kembled \\
Watched & V. & 7 & & \\
Warm & Adj. & 8 & $7-10$ & Bamber $\rightarrow$ Bambered \\
Noise & N. & 9 & & Gurley \\
Window(s) & N. & 10 & & Mollet(s) \\
Laughed & V. & 12 & $12-15$ & Gummer $\rightarrow$ Gummered \\
Living-room & N. & 13 & & Alden \\
Afraid & Adj. & 14 & & Hislop \\
Bed & N. & 15 & & Galpin \\
Old & Adj. & 17 & & Mundy $\rightarrow$ Mundied \\
Asked & V. & 18 & & Pegler \\
Husband & N. & 19 & & Lomax \\
Hand & N. & 20 & &
\end{tabular}

Note: Only past tense verbs were used in the story.

\section{Appendix B}

\section{Vocabulary Post-Test: Description and Examples}

\section{Recognition of spoken form}

[This measure had an aural multiple choice format; participants heard a recording of the target word and three distracters twice and had 5 seconds to check the box corresponding to the correct spoken form of the target word.]

Example:

Participants heard:

Which pronunciation is correct? Please check the box.

Number one [2sec] A bartle [2sec] B bertel [2sec] C burdle [2sec] D bardel [2sec.]

Number one [2sec] A bartle [2sec] B bertel [2sec] C burdle [2sec] D bardel [5sec.]

At the same time, the participants saw on the test page:

Which pronunciation is correct? Please check $(\checkmark)$ the box.

\section{1. $\square$ A $\square$ B $\square$ C $\square \mathrm{D}$}




\section{Recognition of written form}

[This multiple choice test consisted of the target word and three distracters. The same distracters used for the test of spoken form were used for this test.]

Example:

Which spelling is correct? Please check $(\checkmark)$ the box.

1. $\square$ bartle $\square$ bertel $\square$ burdle $\square$ bardel

\section{Recognition of part of speech}

[For this test, the target word was presented in three different sentences. Each sentence used the target word as a different part of speech. Only one of the sentences was correct, and the other two were distracters. In order to avoid any learning effects on the tests that follow, sentences were created in such a way that no clues to the meaning of the target words were provided.]

Example:

Which sentence is correct? Please check $(\checkmark)$ the box.

1. bartle $\square$ It is a bartle. (Noun)

$\square$ He is very bartle. (Adjective)

She bartled. (Verb)

\section{Recognition of syntagmatic association}

[In this test, the target word was presented followed by four choices; one choice was in a sequential relationship with the target word and the other three choices were distracters. All choices were in the same word class. Because the correct option was a target word in the passage, all the distracters were chosen from the passage as well.]

Example:

Which word is more likely to be used with bartle in a sentence? Please check $(\checkmark)$ the box.

$\square$ sit $\square$ go $\square$ open $\square$ stop

\section{Recognition of form-meaning connection}

[In this final test, the target word was presented followed by four options: the original real English word which it had replaced in the text and three distracters. The distracters belonged to the same word class. Because the correct option had not been listened to in the passage, all the distracters were chosen from outside the passage as well.]

Example:

Which is the correct meaning for bartle? Please check $(\checkmark)$ the box.

$\square$ book $\square$ chair $\square$ food $\square$ head 


\section{Appendix C}

\section{Scales Measuring Comprehension and Enjoyment}

[Instructions for these scales were provided orally in Farsi by the researcher.]

The following statements are about "The Monkey's Paw."

1. I understood the story.

1 2 3

4

5

Strongly disagree Disagree Neutral Agree $\quad$ Strongly agree

2. I enjoyed the story.

1 2 3 4 5

Strongly disagree

Disagree

Neutral

Agree

Strongly agree 